\title{
Arte participativo. El trabajo como (auto) representación ${ }^{1}$
}

\author{
//I/I/I/I/I/I/II Ana Amado \\ Universidad de Buenos Aires
}

1. Una primera versión de este trabajo fue publicada en Pensamiento de los confines $\mathrm{N}^{\circ} 25$, Buenos Aires, noviembre de 2009 . 
Resumen El "giro social” contemporáneo del documentalismo audiovisual y de las performances teatrales, plantea una serie de cuestiones éticas y también estéticas alrededor de las formas artísticas vueltas a la representación del padecimiento de los pueblos. Con diferentes variantes, se tiende a conceder a las identidades subalternas el centro de la escena, o de un espacio de exhibición determinado, donde explican o desempeñan acciones de acuerdo a sus respectivas experiencias, sean estas de clase, de género, de edad, sexualidad, pero que en la última década están cada vez más concentradas en el mundo del trabajo o en las consecuencias de su crisis. Los apuntes que siguen abordan esta cuestión y sus paradojas a través de la revisión de algunas experiencias argentinas recientes, entre ellas la película Estrellas, de Federico León y las intervenciones teatrales "Mucamas de hotel" de Lola Arias y "Fábrica”, de Gerardo Neuman.

\section{Palabras claves}

documentalismo, identidades, historia del cine argentino

\section{Abstract}

The "social turn" of contemporary audiovisual documentary and theatrical performances, raises a series of ethical and aesthetic questions about art forms around the representation of the suffering of the people. With different variations, subaltern identities tend to be placed in the center of the scene (or other exhibition space) where they explain or perform actions related to their experiences, which might be signed by class, gender, age, sexuality. In the last decade these identities tend to be increasingly centered on the world of work or on the consequences of the crisis. The notes that follow address this issue and the paradoxes through the review of some recent Argentine experiences, focusing on Estrellas, by Federico Leon and theatrical interventions Mucamas de hotel (Hotel Maids) by Lola Arias and Fábrica (Factory) by Gerardo Neuman.

\section{Key-words}

documentary, identity, Argentina Film History 
El "giro social" del arte contemporáneo en los años noventa y particularmente en la última década, se manifestó con un sesgo peculiar en Argentina a partir de la crisis económica e institucional de 2001 y 2002. El clima de convulsión popular, el paisaje humano y social de la crisis, generaron un gran activismo simbólico volcado través de una variedad de lenguajes y de mundos discursivos que buscaron dar expresión a "una trama sociopolítica históricamente lastimada" (Casullo, 2007: 251).

Las cámaras de cine atravesaron a menudo las fronteras hacia el país del pueblo, en donde rehabilitaron el documental social como herramienta idónea para el activismo político por su poder de visibilizar el territorio de los desheredados y de amplificar las voces de las víctimas sobre sus padecimientos. Ese tipo de registro de los excluidos buscaba, por un lado, obtener un facsímil de la realidad cuya crudeza denunciara por sí misma las consecuencias deshumanizantes del estado de excepción neoliberal implantado en los noventa, y a la vez garantizara algún efecto reivindicativo.

Con el cruce de la frontera hacia los márgenes de las ciudades, el espectáculo de otra humanidad aparecía bajo sus diversos rostros y la percepción de la escena contemplada podía describirse, con palabras de Rancière, ya sea como "llegada a la tierra prometida, retorno al origen o descenso a los infiernos" (1991, p. 42), según la impresión que las condiciones encontradas causaran en los visitantes distinguidos (distinguidos por su saber, o por su condición social). 
La repentina visibilidad de la periferia amplió el abanico de miradas y ejercicios solidarios con sujetos que hasta ese momento sólo centralizaban las preocupaciones políticas del discurso progresista y numerosas iniciativas artísticas concentraron sus esfuerzos en transformar los rasgos más evidentes de la experiencia social objetiva, en dramas atravesados por la subjetividad de sus actores. En las numerosas producciones audiovisuales de la etapa de mayor furor de las consecuencias de la crisis, cuerpos y voces testimoniales expresaron y/o asimilaron valores espaciales y temporales desconocidos, ya sea en su singularidad o en el mapa de las vivencias solidarias recién aprendidas. La secuencia post traumática de esta operación en Argentina consistió casi siempre en el registro de los restos, de las ruinas que en términos humanos y materiales correspondieron a una realidad más promisoria en el pasado, aunque las mismas escenas y acontecimientos se tradujeron con estéticas y procedimientos muy diversos. ${ }^{2}$

El cine y el audiovisualismo local, al igual que la fotografía y algunas tendencias teatrales, no se apartaron del modelo del discurso cultural contemporáneo que frente a las diversas formas de padecimiento de los pueblos, busca dignificar al sujeto de la representación ensayando al menos dos tipos de movimiento para su gesto solidario. Uno de ellos, sólo en parte coincidente con el cine social que mencioné en primer termino, consiste en dar legitimidad a los excluidos elevándolos al terreno del arte, perspectiva que confía en la aparente funcionalidad de una estética de la solidaridad que toma a su cargo la responsabilidad de una "justicia" que supone reparadora. No apunto a cuestionar enteramente su validez ética, pero resulta innegable que este tipo de experiencias, vigorizadas por la cuota de exotismo adherida a la pobreza de los pueblos periféricos, alienta un paternalismo cultural creciente a nivel planetario. La extendida circulación de sus producciones (fotografías, videos, artes plásticas, performances teatrales, etc) por la vía de circuitos globales y de los networks de solidaridad activan un consumo de "afectos participatorios", como sugiere Julio Ramos al aplicar estos argumentos en el análisis de la obra de fotográfica de Sebastiao Salgado. ${ }^{3}$

El otro movimiento o modelo del "giro social" en lo artístico remite al conjunto heterogéneo de prácticas que con el apoyo de instituciones variadas - y una inevitable intervención mediática
2. Si bien existían realizadores que trabajaban en el campo social de manera independiente hacia fines de los noventa (por ejemplo, el prolífico Grupo $1^{\circ}$ de mayo recupera en el film documental Matanza, en su acepción más trágica, las imágenes de los piquetes ocurridos desde el ' 98 hasta fines del 2001), los grupos existentes se articularon con otros nuevos para fundar en diciembre de 2001 la Asociación de Documentalistas de Argentina. La producción de video documentales que registró las puebladas de diciembre, luego las movilizaciones y luchas piqueteras, $\mathrm{y}$ las tomas de fébricas cerradas integró, de lejos, el bloque más nutrido de las producciones de un cine hecho en los márgenes de los circuitos de producción de imágenes. 
3. De "documentalismo lírico" califica Ramos el proyecto fotográfico de Sebastiao Salgado, dirigido a registrar dramas fronterizos de migrantes en sus trabajos o los campamentos que los albergan. Ramos lo describe así: un "lente gran angular abierto a esos monumentales paisajes que remiten, en el imaginario alegórico de Salgado, a la difusa frontera entre naturaleza y cultura en esos paisajes matutinos, de luz fría y neblina, en que la precariedad y el visible caos de los campamentos de refugiados son compensados y redimidos por el aura estética, el operativo del grano que refracta la luz y las imágenes" (RAMOS, 2003). Para Ramos la estetización homogénea de Salgado, además de suturar lo discontinuo, sustenta una "solidaridad abstracta, global, que deshace la especificidad de los contextos específicos de la explotación del sujeto".

4. Estrellas recibió el Premio Especial del Jurado del Bafici 2007, entre otros galardones.
- tiende a la integración social y a la inclusión cultural de segmentos amplios de habitantes de los márgenes, apoyándose en procesos de subjetivación que siguen un trámite contradictorio. La contradicción consiste en espectacularizar la pobreza y de modo simultáneo criminalizarla por distintas vías, en tender densos mantos de sospecha sobre la conducta de los excluidos, mientras simultáneamente se subjetiviza su condición formulándola y profundizándola — para sí mismos y para otros — en tanto identidad colectiva. "Gestión del miedo del Otro", llama Joao Camillo Penna a la aplicación de este mecanismo contradictorio en Brasil, donde - con mecanismos parecidos a los Argentina - en producciones de series televisivas, fílmicas, y de relatos de la vida real reforzados por la actual segmentación de imágenes, se establece con eficacia la doble escena por la que los marginales del Brasil pobre devinieron hoy sujetos/objetos de cultura, sin dejar de ser asociados con una criminalidad siempre latente (ver PENNA, 2009). La "hipertrofia del simulacro cultural como sustituto para la vida", promete salvar del crimen a sujetos que entre otras variadas acciones, devienen integrantes de una población de artistas, ya sea "músicos, bailarines, actores o percusionistas" según la irónica contabilidad de Penna.

\section{2}

Existen sin embargo experiencias atentas a las derivaciones éticas y también estéticas de la alianza entre integración cultural y políticas de representación, o que suponen procedimientos menos atravesados por el inmediatismo del discurso cultural contemporáneo y más decididamente orientados a encarar la práctica artística y social como tentativas críticas. Se acercan a esta condición algunas de las exploraciones recientes de la escena artística local que en segmentos significativos de su producción - el registro fílmico o audiovisual, la performance teatral o en la mezcla de estos lenguajes — , adhieren a la tendencia contemporánea de la salida del arte hacia lo real de las relaciones sociales y a la exhibición.

Una de ellas es Estrellas (2005), provocativo ensayo fílmico realizado conjuntamente por el dramaturgo y director de teatro de vanguardia Federico León y el periodista y videasta experimental Marcos Martinez. ${ }^{4}$ La vanguardia y experimentación formal que ambos 
ponen en juego en sus obras respectivamente teatrales o fílmicas, en este caso procede a cancelar fronteras, fronteras de clase social, de género (de su anterior ficción fílmica León pasa al documental, aunque hay un marcado cruce entre ambos registros en esta película), también al ensamble de disciplinas o lenguajes artísticos. Sin estetizar la miseria de la villa de emergencia donde transcurre pero exhibiendo abiertamente la pobreza de sus habitantes, Estrellas roza la paradoja de los proyectos artísticos que inspirados en el paisaje de la exclusión, generalmente buscan conmover con la indigencia material o humana como decorado. A distancia de la intención sociológica de hacer visible una determinada situación social, el film se construye con las imágenes y sobre todo la voz de los habitantes de la villa, dispuestos a diagramar una ficción propia que los exprese en su situación de pobreza o desocupación, a la vez que reflexionan sobre el arte de asumir esa condición para mejor representarla. ${ }^{5}$

Retomaré más adelante las consideraciones sobre Estrellas para detenerme en un par de ejemplos que refieren también a la interpretación de parte de sujetos seleccionados para "actuar" según sus propias identidades subalternas, procedimiento que se vuelve ostensible por la condición de performances teatrales. Mucamas de hotel, es una obra de Lola Arias que se construye con la intervención protagónica de cinco mujeres que limpian las habitaciones de hotel y que relatan y/o muestran en fotos, audios y/o videos - a espectadores que van a este encuentro en forma individual-, pasajes de sus vidas privadas y su trabajo, todo ello en el espacio de los cuartos donde cumplen sus tareas cotidianamente. En Fábrica, de Gerardo Neumann, los obreros reproducen en el espacio de la fábrica, en vivo y en directo, los movimientos reglados que rigen cada día su relación con la producción y con las máquinas. En uno y otro caso, se asume el lugar de trabajo como escenario naturalizado: el hotel, la fábrica, sitios donde la vida privada los trabajadores son compelidos a dejar de lado sus vidas privadas para asumir cotidianamente la ficción de una identidad laboral: mucama, obrero. Ambos proyectos formaron parte del festival Ciudades Paralelas, integrado por ocho performances o intervenciones realizadas en Buenos Aires durante el mes de diciembre de 2010, como un capítulo especifico de otras intervenciones similares que tuvieron lugar algunos meses antes en Berlín, y que se repetirán luego en Suiza. ${ }^{6}$ El montaje en diferentes contextos y culturas es conceptualmente el mismo, pero
5. En este sentido, creo que puede atribuirse a Estrellas, una intención similar a la que Rancière describe para los films de Pedro Costa que extrema su mirada poética sobre un grupo de marginales caboverdinos y lisboetas que sobreviven entre la droga y la desocupación en villas de chapas que finalmente son demolidas (Ossos, No Quarto do Vanda y Juventude en Marcha). Esta ‘estetización', dice, "significa justamente que el territorio intelectual y visualmente banalizado de la miseria y de la marginalidad es devuelto a su potencialidad de riqueza sensible y compartible" (RANCIÈRE, 1991, p. 81).

6. En el festival Ciudades Paralelas, los dramaturgos y directores teatrales Lola Arias y Stefan Kaegi en su rol de curadores convocaron a otros seis artistas para apropiarse de diferentes espacios de cuatro ciudades (Berlín, Buenos Aires, Zurich, Varsovia) y transformarlos en escenarios temporarios. Las ocho intervenciones, que incluyen los proyectos Mucamas y Fábrica tienen en común la investigación sobre la subjetividad puesta en juego en los espacios públicos como las bibliotecas, el shopping, la fábrica, las estaciones de tren, los tribunales y en los espacios privados, como en los departamentos de edificios o las habitaciones de hotel. 
7. En el Kwadrat Project Space de Berlín se exhibe hasta enero de 2011 una muestra colectiva con el título World is work, donde un grupo de artistas invita a reflexionar desde una distancia crítica acerca de los cometidos que ocupan la mayor parte de nuestro tiempo: el trabajo, o la falta del mismo. Santiago Sierra

- quien rechazó recientemente el Premio Nacional de Bellas Artes 2010 de España - interviene en la muestra con una obra referida a la explotación documentando en imágenes un trabajo absurdo encargado a unos inmigrantes checos: la inviable construcción de cubos de arena de un metro de ancho. con los ajustes o cambios que impone los participantes, sus lenguas, su historia, su cultura. La experiencia de Neumann en Berlin se ejecutó en la fábrica de Mercedes Benz, con 4000 empleados, mientras que en Buenos Aires, la de ceras Suiza que sirvió de espacio para su experiencia cuenta con 40 trabajadores. Y si bien la instalación de Arias contaba con una base edilicia común (diseños, colores, reglamento, etc) por tratarse de un hotel perteneciente a la misma cadena internacional con réplica en estas tres ciudades, las características del grupo de encargados de la limpieza variaba de ser un grupo mixto de hombres y mujeres que emigraron de Africa, Vietnam o China a uno compuesto solamente por mujeres, no extranjeras sino venidas del conurbano de Buenos Aires, o de lejanas provincias norteñas. En ambos casos, más allá del énfasis en las identidades de trabajo, en el relato y las acciones de los obreros y mucamas protagonistas, ocupa un lugar preponderante sus respectivas historias personales alternando con sus ocupaciones propiamente dichas, lo cual convierte a estas piezas en instalaciones biográficas, para asignarles un nombre o categoría.

Claire Bishop llama "delegaciones" al gesto de los artistas de convocar a no profesionales para ejecutar las acciones de su inspiración (BISHOP, 2010/2011). Entre las variantes y diferentes formatos de performances delegadas que analiza Bishop, se encuentran aquellos en los que se solicita a los participantes como sucede en las obras de Arias y de Neumann - desempeñar acciones "según sus propias identidades", en un espacio de exhibición determinado. Identidades a partir de la raza, la clase, el género, la sexualidad o la edad y en la última década, menos lúdica que las anteriores, centrada sobre todo en le mundo del trabajo o de la consecuencia de su crisis. Las experiencias más extrema son las obras - o intervenciones, o instalaciones en vivo - del madrileño Santiago Sierra, dedicadas en la última década al mundo del trabajo, sobre todo a la realidad de la miseria y de la desocupación en los países de centro y Sudamérica, y de las condiciones de explotación a las que invariablemente son sometidos los indocumentados tanto en este continente como en el primer mundo. ${ }^{7}$ La crítica a las obras de Serra se centra en el procedimiento mismo de sus obras, cuyo montaje repite la inequidades del capitalismo globalizado al subcontratar, como sucede en los países centrales, para distintos trabajos a obreros mal remunerados de países en desarrollo. Serra 
hace de la contratación a los participantes, sin embargo, un punto clave de sus puestas: esta acción se cumple a través de agencias de empleo y la transacción financiera se convierte en un dato central, al exhibir los detalles de cada pago en cada función y convertir de este modo el sistema económico de la obra - y por extensión, el general - en el principal punto de referencia.

En los casos de Mucamas o Fábrica, este tipo de pactos no se hacen ostensibles, ya que su objetivo es poner de manifiesto las identidades de los participantes como trabajadores y a éstas en relación con sus biografías. En Mucamas, la intervención de cada una de ellas se cumple en una habitación con una puesta en la que su presencia está siempre mediada por algún tipo de imagen: fotografías, videos en los que interactúa desde el la pantalla de TV convertido en monitor interactivo con cada espectador, voces grabadas contando pasaje de sus vidas. Según el énfasis, estas situaciones indeterminan el origen documental o la disposición ficcional de las descarga de un relato donde se mezclan la vida privada y la laboral, en medio de decorados que en cada cuarto asume el sesgo de cada historia. ${ }^{8}$ Sólo al final del recorrido (diez minutos muy reglados en cada uno de los cinco cuartos) alguna de las mucamas con cuya historia se estableció un lazo de cierta intimidad y hasta simpatía, sale al encuentro del espectador y tras guiarlo por dependencias del hotel - que se atraviesan como bambalinas de la puesta principal —, lo deposita en la salida. Allí es donde tratará de reaccionar o procesar los retazos de la vida real que se desplegaron ante su presencia casi como en una función privada.

En Fábrica, en cambio, no hay privacidad, tampoco mediaciones, porque aquí se reproducen las reglas del trabajo, no se las relata. La obra se despliega durante el tiempo de trabajo y con la fábrica funcionando. Obra y trabajo real se superponen. Obreros que hacen autos o fabrican y empaquetan cera, y que en el proceso reiterado de exhibición para un grupo de espectadores, devienen actores. Actores y a la vez guías de los espectadores, que se desliza por el espacio de la fábrica sin saber en cuál de las "dos obras" se encuentra. El film Estrellas, de León, a semejanza de las performances teatrales de Arias o de Neumann, permite a su protagonista testimoniar sobre su condición e identidad, aunque a través de ese mismo discurso subraya la falta de límites entre lo real y lo ficcional de esa condición y de esa identidad cuando se elige representarlas.

\footnotetext{
8. El énfasis autobiográfico es una marca de las obras teatrales más recientes de Lola Arias, entre ellas Mi vida después (2009-2010), en la que tres actores y tres actrices se interpretan sus propias biografías, como descendientes de padres desaparecidos o comprometidos políticamente durante la dictadura de los 70 y relatan sus experiencias en un límite impreciso entre lo documental y la ficción escenográfica.
} 
Estrellas establece un recorrido por las ideas de Julio Arrieta, habitante de la Villa 21, una de las más abigarradas villas de emergencia del sur de Buenos Aires, donde se desempeña como manager de actores de la villa y dirige una productora que arma decorados y sets de filmación. A través de su discurso Arrieta revela una clara autoconciencia acerca de la vigencia estética y cultural de los signos de la marginalidad y de los estereotipos construidos sobre la pobreza, para la cual propone distintas maneras de representarla, plantea la discusión entre la elección de actores profesionales y los que no lo son y defiende el valor de la autogestión en ese trabajo, entre una amplia serie de cuestiones. Se plantea también el cruce entre realidad y ficción, en diálogo con el género de ciencia ficción a través de un film imaginado e interpretado por Arrieta, cuyas imágenes registradas previamente por otro director son parcialmente integradas.

El trabajo de León en Estrellas consistió en instalar como territorio específico "la ciudad de los pobres", la villa de emergencia transformada en un gran set de filmación por sus mismos habitantes y en encuadrar a los pobres y el discurso de los pobres para hablar no de pobreza como precariedad de existencia, sino de la pobreza como actuación, como representación. Registrar no las manifestaciones visuales mas evidentes de la desocupación, de la carencia de trabajo, de la nueva pobreza con la potencia significativa de los pormenores que la constituyen, sino la inscripción de sus huellas en los cuerpos y rostros, las maneras posibles de construir una visión sobre la superficie de una apariencia y las formas de devolución del Otro desde esa apariencia autopercibida. Si los parámetros de percepción o autopercepción de los individuos de clases sociales carenciadas mudaron junto con la identidad de los sujetos registrados, el acierto de León fue vincular al propio cine con esas mudanzas y de asimilar a sus imágenes la renovación de formatos de representación y por lo tanto, la necesidad de alterar o invertir el emplazamiento de los dispositivos de registro.

Es pertinente recordar aquí que el cine estrenó sus cámaras emplazándolas frente a una fábrica, para el caso, la fábrica de los inventores y dueños de las cámaras, los Hermanos Lumière, desde donde filmó a un centenar de trabajadores saliendo por sus portones al cabo de un día de trabajo. El film proyectado muestra la misma escena captada en tres ocasiones diferentes desde la misma posición 
de la cámara, dando la impresión de un flujo ininterrumpido de trabajadores, más allá de que cada jornada esté enmarcada por la apertura y el cierre de los grandes portones de la fábrica Lumière. Así, puede decirse que desde el inicio la fuerza omnisciente de la cámara, buscando cómo exhibirlos con el ritmo y la regularidad de una "verdadera" salida, transformó a los obreros en un ejército de extras. Por encima de la distancia - de tiempos de lenguajes es precisamente la repetición el elemento que convierte en ficción una ocurrencia documental, como sucede con los trabajadores de Fábrica de Gerardo Neumann, y de Mucamas de hotel, de Lola Arias.

A lo largo del siglo XX, las cámaras enfocaron una y otra vez hacia la fábrica en busca del proletario, del obrero, del trabajador, cuyas alternativas ocuparon las narrativas más politizadas en diversas cinematografías durante los años sesenta y setenta. Refiriéndose a la película de los Lumière, Harum Farocki observa que antes que la dirección cinematográfica interviniera para condensar al sujeto en un personaje, fue "el orden industrial el que sincronizó la vida de muchos individuos" (FAROCKI, 2003). Esto en el sentido de que tal orden les permitía por ejemplo, salir en un instante determinado (por la indicación de quien los filmaba, en ese caso), ya que a hasta ese momento estaba contenidos por los portones de salida de la fábrica, que constituían una suerte de marco. El orden del trabajo, para Farocki, sincroniza a obreras y obreros, el portal de la fábrica los estructura y de esta compresión surge la imagen de una fuerza laboral. Quienes trasponen las puertas de esa fábrica, por lo tanto comparten esa imagen, la de trabajadores, como algo fundamental. "La imagen se acerca al concepto y, por ese motivo, pudo transformarse en una figura retórica”, figura que se encuentra en tantas películas sobre las fábricas, el trabajo y los proletarios durante los años sesenta y setenta. ${ }^{9}$

De manera oblicua toma posición ante esa tradición para invertir su signo. Alude entonces a la pobreza, a la desocupación, al trabajo inexistente, a la representación como trabajo y al trabajo de la representación, desde el mismo inicio con una imagen que puede interpretarse como el reverso puntual de las registradas por Lumiére. En ese plano, evitando toda definición visual o auditiva, declinando la mostración neta que procuraba la filmación en exteriores del frente de la fábrica y sus trabajadores, y antes aún de los créditos de presentación del film, la cámara de Estrellas comparte
9. Partiendo de las imágenes de los hermanos Lumière, Harun Farocki hace un montaje recopilando escenas de 100 años de la historia del cine que tratan el tema del trabajo. En su Trabajadores saliendo de la fábrica (1995) Farocki extrae de las imágenes las reflexiones sobre la iconografía y la economía de la sociedad de trabajo, y a la vez sobre el cine mismo, cuya función fue, desde sus comienzos, convocar a los espectadores "a la salida de la fábrica" y transportarlos a la esfera privada de sus ficciones. 
la oscuridad, la indeterminación de un espacio interior con un grupo anónimo de personas del que sólo se perciben voces inciertas y exaltadas. Finalmente se abren abruptamente los portones y la cámara acompaña, confundida entre los cuerpos, detrás de ellos, la estampida hacia el exterior, sin recurrir (al menos en este punto del film) a un contracampo que agregue una visión más explícita sobre esa muchedumbre de dimensiones módicas. La escena anticipada reingresará más tarde en el interior de una secuencia que dejará en claro su pertenencia a un film de ciencia-ficción imaginado por Arrieta y rodado en la villa. Tras ese inicio opaco en su significación, Julio Arrieta informa que se trataba de un grupo de trabajadores desocupados que aspiran a salir de esa situación deviniendo actores y actrices dispuestos a representar en cine o televisión papeles adecuados a su condición de pobres. Es decir, roles en los que la pobreza y la desocupación terminan por imponerse visualmente por vía de la apariencia como sello físico, corporal. En un pasaje de su intervención Arrieta define a sus representados - y a él mismo - como "portadores de cara", e ideales para "hacer de lo que son". Ser "portador de cara" consiste en exhibir una apariencia que presenta rasgos previamente definidos por la jerga policial, es la policía quien condena a sospechosos por "portar cara" de ladrón, de proxeneta, de prostituta, etc. Ser portador de cara implicaría la aceptación tácita de un destino virtual de prontuario y en este sentido asumir, por lo tanto los papeles asignados dentro del programa de exclusión constitutivo de nuestras sociedades. ${ }^{10} \mathrm{El}$ documental de

10. De hecho, Arrieta recuerda antecedentes de la participación de muchos de ellos en series de televisión sobre ambientes carcelarios y marginales, series que alcanzaron niveles altos de audiencia como Tumberos o Disputas, ambas dirigidas por el realizador cinematográfico Adrián Caetano y estrenadas poco después de la crisis de 2001.
León incorpora las imágenes de los protagónicos evocados, junto a otros ejemplos, como el de films publicitarios donde participan los actores villeros y en los que paradójicamente asumen roles tanto de ladrones como de policías, es decir su aspecto físico correspondería a personajes tipificados como pertenecientes a un lado y otro de la ley. De modo aún más complejo, si cabe, Arrieta y su gente expresan en su discurso los argumentos que la gestión cultural institucional aplica en su territorio para la incorporación estratégica de los excluidos de los pobres, los desocupados, las víctimas - , y lo llevan a su propia práctica. Así, los habitantes de la Villa 21, transmutados en elenco artístico autogestionario, asumen la subjetivación penal/cultural a la que refiere Penna (2009) aunque en este caso culturalizan el crimen hasta disolverlo simbólicamente en sendas apariencias.

$\mathrm{Si}$ se piensa que toda película por diversos procedimientos 
inventa su propia lógica figurativa puede decirse que las figuraciones fílmicas del cuerpo que ofrece Estrellas a través de la galería de personajes Tipo o Estereotipos clasificados por Arrieta, conlleva una suerte de tratamiento de la corporalidad como motivo u objeto hermenéutico. A invención de la lógica figurativa del film de León, o mejor dicho de aquella inventada por Arrieta para sí mismo y para sus "representados" y que León reconduce en Estrellas tiene precedentes que la remiten, no sin ambigüedad, a un linaje histórico y artístico. Por ejemplo, al de algunas obras de fines de los años sesenta y setenta, que situadas al margen de cierto fetichismo historicista en relación a las imágenes del trabajo, y específicamente a la "figura" canonizada del trabajador, introdujeron brechas significativas en el sistema dominante de representaciones ideológicas. Entre aquellos antecedentes que pueden ponerse en relación con Estrellas se encuentra centralmente "La familia obrera" de Oscar Bony, artista que en 1968 expuso, en el Instituto Di Tella y en vivo y en directo, una familia obrera integrada por un padre - el obrero, vestido con un flamante uniforme de trabajo - , su esposa y un niño que a su lado leía o realizaba tareas escolares. El grupo familiar, señalado por la marca laboral del jefe de familia, se exhibía en una pequeña tarima, a la altura de los ojos de los espectadores durante ocho horas por día. A su lado, un cartel explicaba: "Luis Ricardo Rodríguez, matricero de profesión, percibe el doble de lo que gana en su oficio, por permanecer en exhibición con su mujer y su hijo durante la muestra". Bony "alquiló" una familia obrera para exponerla, admitiendo que con ello asumía implícitamente el rol de torturador y explotador." "La Familia Obrera" se convirtió en una referencia a nivel mundial del conceptualismo y el arte político en Latinoamérica, antecedente que se hizo explícito en la $29^{\mathrm{a}}$ Bienal de Arte de Sao Paulo, dedicada a la relación entre Arte y política, que exhibió una reproducción fotográfica de grandes dimensiones de esta obra. ${ }^{12}$ Los happening o performances de las décadas del sesenta y setenta, décadas preocupadas por la correcta politización del arte, tenían una vocación edificante, respondían al "modelo pedagógico de la eficacia del arte”, como señala Rancière, pedagogía que entonces se impartía en los espacios museísticos (RANCIÈRE, 2010, p. 55). Salir de allí al mundo real no soluciona las paradojas que acechan las intencionalidad política de este tipo de intervenciones, pero en ese afuera se anudan relaciones en torno a nuevos procesos
11. Para el curador y crítico de arte Marcelo Pacheco, esto impactó en la derecha, y también en la izquierda artística y provocó una verdadera fractura en un campo de batalla político ideológico que se abrió en el arte argentino de aquella etapa. De ahí que la obra de Bony resulta clave para entender determinados debates posteriores en la relación arte y política. Véase la presentación que Pacheco realiza en el Catálogo de la retrospectiva dedicada a la obra de Bony en el MALBA Museo de Arte Latinoamericano de Buenos Aires (PACHECO, 2008).

12. La $29^{a}$ Bienal de Sao Paulo tuvo lugar entre el 25 de septiembre y el 12 de diciembre de 2010. Esta versión de la Bienal contó con la dirección curatorial de Moacir dos Anjos y Agnaldo Farias, y su equipo de curadores: Fernando Alvim, Rina Carvajal, Yuko Hasegawa, Sarat Maharaj, Chus Martínez. 
y producciones subjetivas de los sujetos produciendo sus propias imágenes en un escenario que les pertenece.

En Estrellas, una secuencia reformula, es decir ficcionaliza sin proponérselo lo que puede leerse como versión actualizada de la familia obrera de Bony, recuperando las acciones previas que hoy conducen a una iconografía similar, pero rotundamente más precaria. En ese pasaje, Julio Arrieta realiza una demostración acerca de las destrezas constructivas de la gente de la villa, al levantar en un descampado y velocidad récord, una casilla similar a "aquellas que se buscan como locaciones de villas de emergencia en muchas películas", según explica (y ejemplifica con el director Alan Parker quien decidió ignorar estas habilidades para construir las casillas de los pobres en el film Evita que rodó en la Argentina con Madonna). $\mathrm{Al}$ pie de la imagen el contador del video marca el lapso empleado en la edificación - 3 minutos, 26 segundos -, con ocupación del monoambiente de chapas por una trinidad familiar, padre, madre e hija, que la imagen detiene al final un instante, como quien subraya los atributos del grupo para la representación. Sucede lo mismo con los materiales: la fragilidad de la casilla enfatiza su semejanza con una de utilería, de manera que resulta indistinguible la real de la escenográfica, convirtiendo así la marca de una escasez en una realidad filmada. Así, las propias señales de la precariedad no se incluyen exactamente como rasgos estructurales de la pobreza aunque sin duda lo son - sino como ademanes acentuados de la puesta en escena, como parte de la iconografía que arma el referente canónico de la clase social a la que pertenecen Arrieta y su familia. Significados similares pueden extraerse de la familia obrera exhibida por Bony en los sesenta, pero a diferencia de su exposición silenciosa, en Estrellas el discurso verbal de Arrieta resalta la contradicción de los estereotipos que reunidos, configuran una identidad y junto con ella una adjudicación territorial, un cuerpo, una apariencia.

La propuesta de León abre así una serie de cuestiones encajadas referidas al vínculo entre trabajo y sociedad, entre exclusión e integración, entre representación y realidad, también a la explotación y manipulación de los pobres y la aceptación de parte de ellos, aparentemente acrítica o resignada, de esa condición. También a la distancia entre la experiencia de vida (ellos son pobres) y la representación estética (deben hacer de pobres? Y sobre todo, de pobres que responden al imaginario extendido sobre la apariencia del pobre?). 
Estas lógicas heterogéneas movilizan una serie de cuestiones, de algún modo consideradas por Federico León que junto con Martín Rejtman elaboró una peculiar película de ficción que de manera oblicua se refiere a la coincidencia, en una obra teatral, entre identidad del actor y personaje. "Hacer de otro no es cualquier cosa", es la frase que abre Entrenamiento elemental para actores (Buenos Aires, 2009) que precisamente explora la relación entre actuación y formas "naturales" o realistas de la representación. Interpretada por niños que asisten a un taller de actuación teatral y sometidos a consignas muchas veces impracticables para su comprensión, o para su destrezas física, Entrenamiento... equipara a la niñez con una suerte de identidad radical o de estado intransferible - en lo generacional y en la apariencia - , ya que se apoya en la paradoja de enseñar reglas de actuación a niños quienes, se sabe, nunca interpretan otra cosa que su propia condición de niños.

Rozando lo real o lo ficcional, las obras mencionadas aquí buscan un efecto estético y además político, en el sentido de impactar de alguna forma en el ánimo del espectador, expuesto ante aquellos retazos de la vida real que recibió en su pasaje por los cuartos de hotel, recorriendo una fábrica o ante la imágenes que muestran el corazón de una villa de emergencia. "El espectador es invitado a vivir algo sin saber bien cuál es su rol, dónde termina lo ficcional y dónde empieza lo real, si se trata de un retrato de los otros o si se trata de nuestra forma de mirar a los demás", describe con lucidez Lola Arias (BISHOP, 2010/2011, p. 58). Admitir que estas obras descolocan al espectador en su rol es pensar, con Rancière, que estas acciones frente a las obras comentadas no alteran sustancialmente su actitud de concurrente pasivo a la exposición sobre las vida miserables cuyo pormenor conoce en estas narraciones (RANCIÈRE, 2010, p. 78). La falta de mediación de actores como sucede en la escena tradicional, sería en cierto modo suficiente para gestar una instancia reflexiva: en lugar de una "pedagogía de la mediación representativa”, y una vez deshecha la distancia entre mundo y representación, las obras analizadas ofrecen una "pedagogía de la mediación ética”. Concebidos en tiempos de post autonomía del arte, del arte deviniendo vida estos ejemplos, son post brechtianos de algun modo, ya que junto con la mediación también cae el efecto de distancia con lo representado, cuestión que los años setenta juzgaban imperiosa para liberar una acción reflexiva. 
Si antes, en un contexto que marcó profundamente el llamado Nuevo Cine Latinoamericano en los años sesenta y setenta la noción que animaba la dramaturgia teatral o cinematográfica era la de síntesis, la capacidad de un personaje para significar un grupo, una clase, una época, hoy importa más pensar en personajes singulares que plantean una interrogación particular al mundo (Estrellas), o permiten interrogar al mundo y sus formas a través de sus experiencias (Mucamas,Fábrica) y que parten de la idea común de entender y vivir el mundo como representación. Referencias y perspectivas a la vez individuales y colectivas que responden a una determinada situación en el espacio, en el tiempo (una manera de habitar, de ocupar un lugar, una geografía, de responder a una locación), en un proceso que pone en evidencia los cuerpos, la apariencia, las figuras comunitarias de lo local y de lo regional organizando el acontecimiento sonoro en acuerdo o en colisión con lo visual en las formas de representación de la pobreza o la necesidad. 


\section{Bibliografia}

BISHOP, Claire. "Performance delegada: subcontratar la autenticidad". In: Otraparte. n. 22, Verano, 2010/2011.

CASULLO, Nicolás. Las cuestiones. Buenos Aires: Fondo de Cultura Económica, 2007.

FAROCKI, Harun. Crítica de la mirada. Buenos Aires: Ediciones Bafici, 2003.

FOSTER, Hal. El retorno de lo real. La vanguardia a finales de siglo. Madrid: Akal, 2001.

LONGONI, Ana y MESTMAN, Mariano. Del Di Tella a Tucumán Arde. Vanguardia artística y política en el '68 argentino. Buenos Aires: Ediciones El cielo por asalto, 2000.

LUDMER, Josefina. Aquí América Latina. Una especulación. Buenos Aires: Eterna Cadencia, 2010.

PACHECO, Marcelo. Oscar Bony. El mago. Obras 1965 / 2001. Buenos Aires: Catálogo, MALBA Museo de Arte Latinoamericano de Buenos Aires, 2008.

PENNA, Joao Camillo. "Criminalizacion y culturalizacion de la pobreza”. In: Pensamiento de los Confines 23/24, abril, 2009.

RAMOS, Julio. "Coreografías del terror: justicia estética de Sebastião Salgado”. In: FERNÁNDEZ BRAVO, Álvaro; GARRAMUÑO, Florencia y SOSNOWSKI, Saúl. Sujetos en tránsito. (in)migración, exilio y diáspora en la cultura latinoamericana. Buenos Aires: Alianza Editorial, 2003.

RANCIÈRE, Jacques. Breves viajes al país del pueblo. Buenos Aires: Nueva Visión, 1991. El espectador emancipado. Buenos Aires: Manantial, 2010. 